\title{
The Algorithm Design and Driving Force System in Thematic Robot of Paddy Farming
}

\author{
Syaiful Amri ${ }^{a, 1, *}$, Reza Septiadi a,2 \\ a Politeknik Negeri Bengkalis, Bengkalis, Indonesia \\ ${ }^{1}$ syaifulamri@polbeng.ac.id *; ${ }^{2}$ aderezaseptiadi@gmail.com; \\ * corresponding author
}

\section{ABSTRACT}

Keywords

Thematic Robot

Rubber Track

Joystick

Pneumatic
Indonesia Thematic Robot Contest (Kontes Robot Tematik Indonesia (KRTMI)) is one of division in Indonesia Robot Contest (Kontes Robot Indonesia (KRI)) which tailor to the nation necessity that is demanding to be resolved. In this KRTMI division robot contest, the robot, that was able to be controlled by a remote wirelessly, was designed in order to perform paddy planting simulation, pluck grasses among paddies, and harvest paddy. In this robot contest, the robot was also designed to be able to pass through mushy soil while planting paddy and plucking grasses. From the robot concept that is based on the rules, the robot used primary driving force with two DC gearbox motor which was paired with rubber track type wheels to be able to pass through mushy soil. While for performing paddy planting and grass plucking, a combination of DC gearbox motor and pneumatic was applied. The entire operation of the robot was controlled with wireless joystick command by a robot operator. The result of this research could be tested for its motor driver response efficiency and relay on-off control for the pneumatic which was controlled wirelessly through a joystick. The testing results were efficiency of $99 \%$ and control response success of $100 \%$.

\section{Introduction}

Technology in field of robotics nowadays has been much utilized for farming in many countries. Indonesia Thematic Robot Contest (Kontes Robot Tematik Indonesia (KRTMI)) was held for the first time in 2019 considering the circumstances and needs of the nation. Themes in a division of Indonesian Robot Contest (Kontes Robot Indonesia (KRI)) up to 2018 mostly adopted the similar robot contest which is held abroad. As for the contest theme of this thematic robot was "Paddy Farming Robot". Paddy farming thematic robot was controlled remotely (wireless) to perform paddy planting simulation, plucking grasses among paddies, and harvesting paddy[1]. Paddy farming thematic robot was also designed to be able to pass through mushy soil while planting paddy and plucking grasses.

As there is KRTMI with a theme of paddy farming robot, this is expected to become a medium to develop and extend ideas to improve food farming productivity through automation and robotics[1]

\section{The Proposed Method/Algorithm}

\subsection{System Diagram Block}

This research used Arduino Mega as the primary controller of controller from paddy farming thematic robot by using Arduino Mega internal PWM to adjust gearbox motor speed[2][3]. 


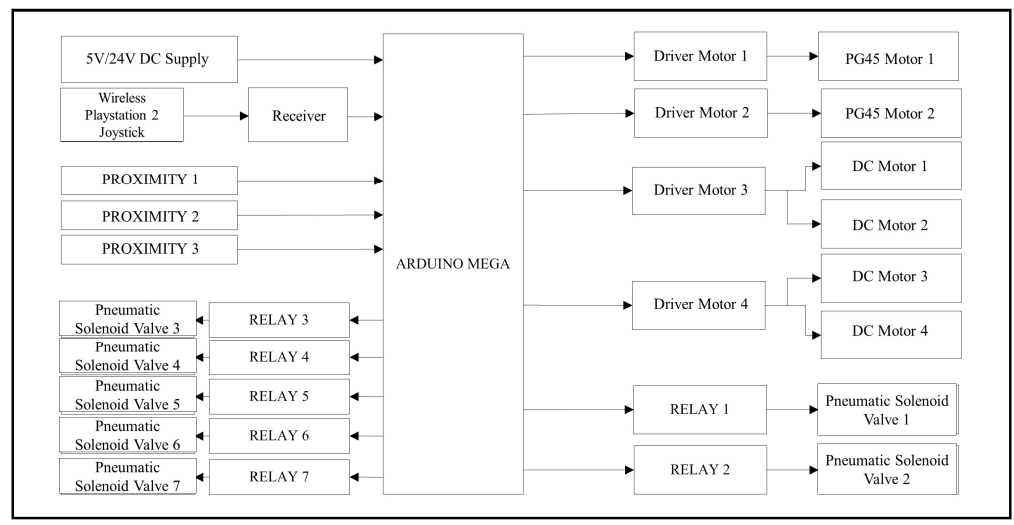

Fig. 1.System Diagram Block of Thematic Robot

The functions of all components which are in system design diagram block figure above can be described below:

- Driver Motor

- Driver motor acted as controlling the speed of PG45 Motor and 12 Volt DC Gearbox Motor.

- $12 \mathrm{~V}$ DC Gearbox Motor

- 12 Volt DC Gearbox Motor acted as an activator for pneumatic lifting lever.

- $12 \mathrm{~V}$ DC Gearbox Motor

- PG45 Motor acted as an activator for rubber track.

- Battery

- Battery was used to provide power supply to the four driver motors, PG45 motor, and solenoid valve.

- Power Bank

- Power bank acted as the power supply to all controllers and electronics.

- Wireless Playstation 2 Joystick

- Playstation joystick acted as a remote control.

- Relay

- Relay is a digital switch which acted as a voltage connector and breaker in pneumatic solenoid valve.

- Pneumatic Solenoid Valve

- Pneumatic solenoid valve acted as an exit and entry wind regulator.

- Proximity

- Proximity acted as a gab detector between paddy seed clamp and paddy seed.

- Cylinder Pneumatic

- Pneumatic cylinder acted as an activator for the sphere clamp and an activator for moving back and forth of the clamp arm.

\subsection{Robot Primary Driving Force}

Maximum dimension of the overall robot is $50 \times 50 \mathrm{~cm}$ based on the rules. Berdasarkan aturan, bahwa dimensi maksimal keseluruhan robot adalah $50 \times 50 \mathrm{~cm}$. The robot primary driving force used two pieces of DC gearbox motor which were powered by BTS7960 driver. 


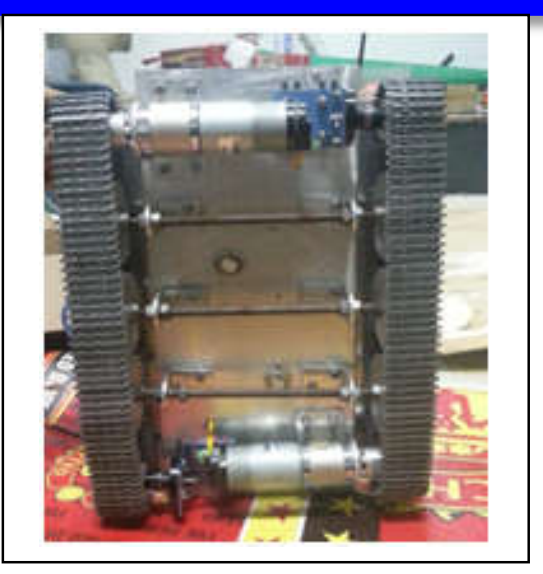

Fig. 2.Robot Chassis Design

\subsection{Designing the Cutter and Clamp}

The design of cutter and clamp can be seen in Figure 3.

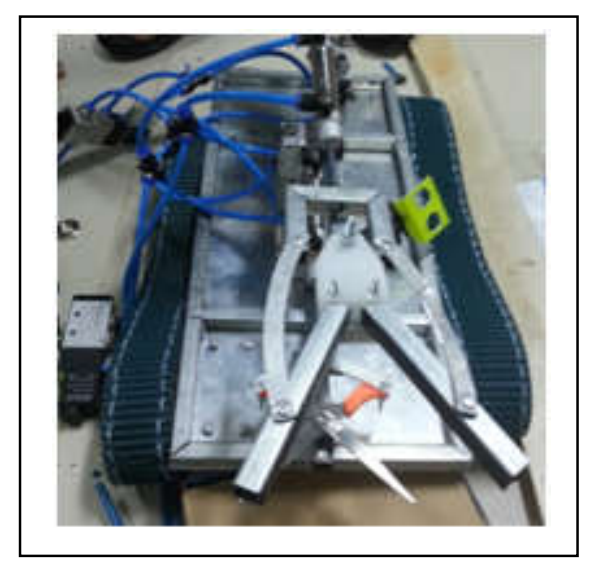

Fig. 3.Cutter and Clamp Design

One of the tasks of paddy farming thematic robot was able to perform paddy planting simulation, plucking grasses among paddies, and harvesting paddy.

\subsection{Making the Overall Robot Chassis}

Making the chassis robot was firstly started by designing the chassis. Designing used Sketchup software application in order to acquire a 3D design result. The design of mechanical body or robot chassis can be seen in Figure 4.

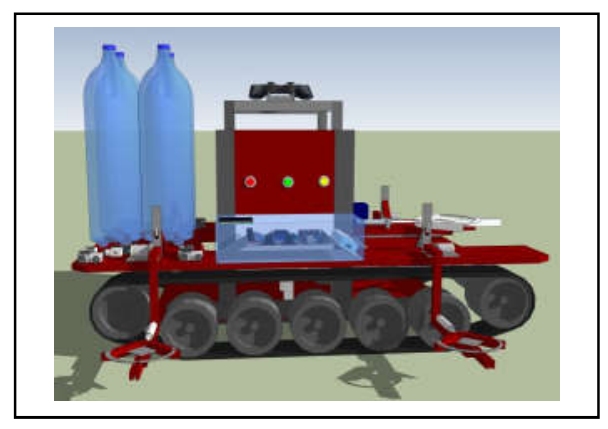

Fig. 4. The Overall Robot Chassis

The main ingredient used to make robot chassis was holo iron by $1 \mathrm{x} 1 \mathrm{~cm}$ square. By using holo iron, the robot was expected to be tough while doing maneuver or crashing with hard surface. Aluminum plate with $0,5 \mathrm{~cm}$ thick was used for the lowest base as a prop or suspension base of motor support[5]. Holo iron $1 \times 1 \mathrm{~cm}$ square was used in the entire body of the robot. The mechanic result of the robot chassis that has been created based on the design can be seen in Figure 5. 


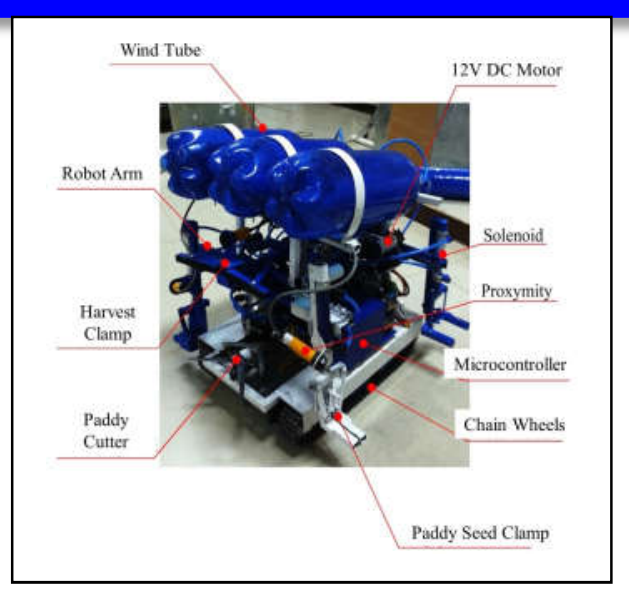

Fig. 5.Chassis Result of the Entire Robot

\section{Method}

\subsection{How the System Works}

The robot will work in accordance to instructions given by the robot operator through which a joystick that is connected wirelessly to the robot[6].

As for explanations for the algorithm flowchat figure are described below:

- Start indicates the processor started working.

- Initialization is an introduction of input and output components to microcontroller.

- Joystick connection check is a connecting process between a joystick and joystick receiver.

- "Is a joystick connected?" is a decision making process to determine whether a joystick connection with receiver are already connected. If the answer is "Yes", then the robot is ready to be controlled. If it is "No" then connecting the joystick to the receiver will be done repeatedly until it succeed.

- Joystick button check is a button pressing process on the joystick.

- "R1 + up arrow button are pressed?" is a decision making process to determine whether R1 and up arrow button in a joystick are being pressed. If the answer is "Yes", then the robot will move forward as long as those two buttons are being pressed. If it is "No", the robot will not move at all. The operator needs to perform a checking on which button that is going to be pressed.

- "R1 + down arrow button are pressed?" is a decision making process to determine whether R1 and down arrow button in a joystick are being pressed. If the answer is "Yes", then the robot will move backward as long as those two buttons are being pressed. If it is "No", the robot will not move at all. The operator needs to perform a checking on which button that is going to be pressed.

- "R1 + right arrow button are pressed?" is a decision making process to determine whether R1 and right arrow button in a joystick are being pressed. If the answer is "Yes", then the robot will move to the right as long as those two buttons are being pressed. If it is "No", the robot will not move at all. The operator needs to perform a checking on which button that is going to be pressed. 


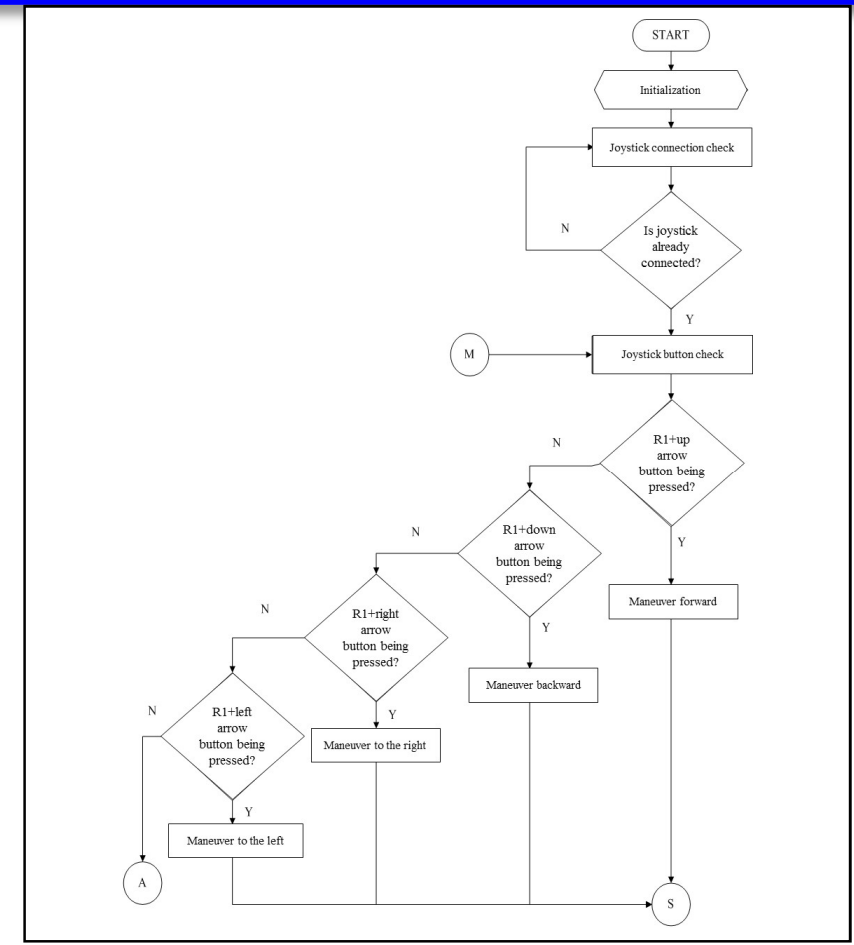

Fig. 6.Joystick Command Sub1

- "R1 + left arrow button are pressed?" is a decision making process to determine whether R1 and left arrow button in a joystick are being pressed. If the answer is "Yes", then the robot will move to the left as long as those two buttons are being pressed. If it is "No", the robot will not move at all. The operator needs to perform a checking on which button that is going to be pressed.

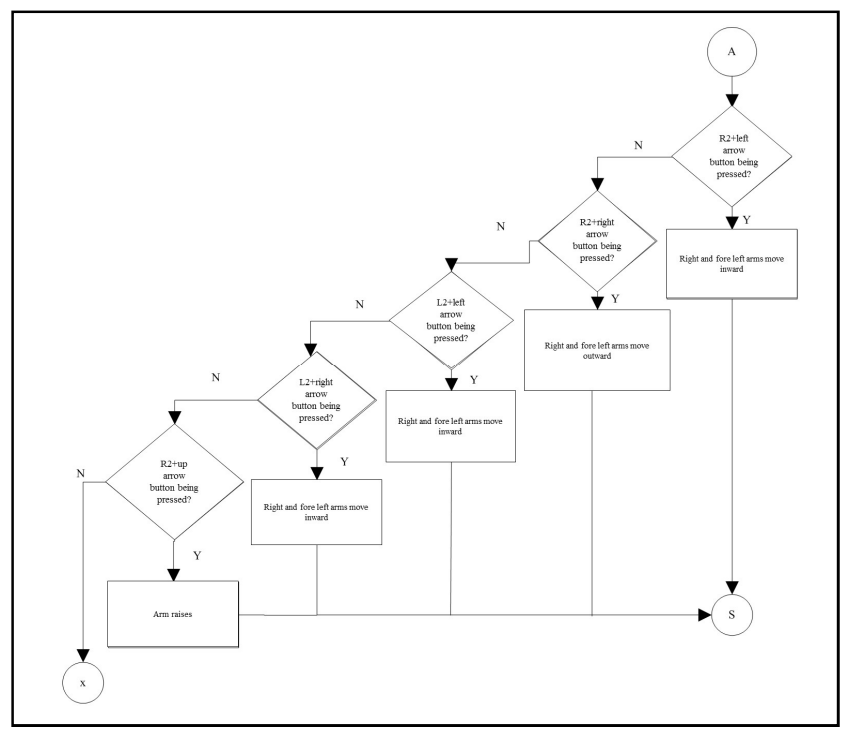

Fig. 7.Joystick Command Sub2

- "R2 + right arrow button are pressed?" is a decision making process to determine whether R2 and right arrow button in a joystick are being pressed. If the answer is "Yes", then 12V DC motor will be activated and the robot hind arm will move outward. If it is "No", the operator needs to perform a checking on which button that is going to be pressed.

- "L2 + left arrow button are pressed?" is a decision making process to determine whether L2 and left arrow button in a joystick are being pressed. If the answer is "Yes", then 12V DC 
motor will be activated and the robot fore arm will move inward. If it is "No", the operator needs to perform a checking on which button that is going to be pressed.

- "L2 + right arrow button are pressed?" is a decision making process to determine whether L2 and right arrow button in a joystick are being pressed. If the answer is "Yes", then 12V DC motor will be activated and the robot fore arm will move outward. If it is "No", the operator needs to perform a checking on which button that is going to be pressed.

- "R2 + up arrow button are pressed?" is a decision making process to determine whether R2 and up arrow button in a joystick are being pressed. If the answer is "Yes", then solenoid valve 1 and 2 will be activated and the pneumatic will rise. If it is "No", the operator needs to perform a checking on which button that is going to be pressed.

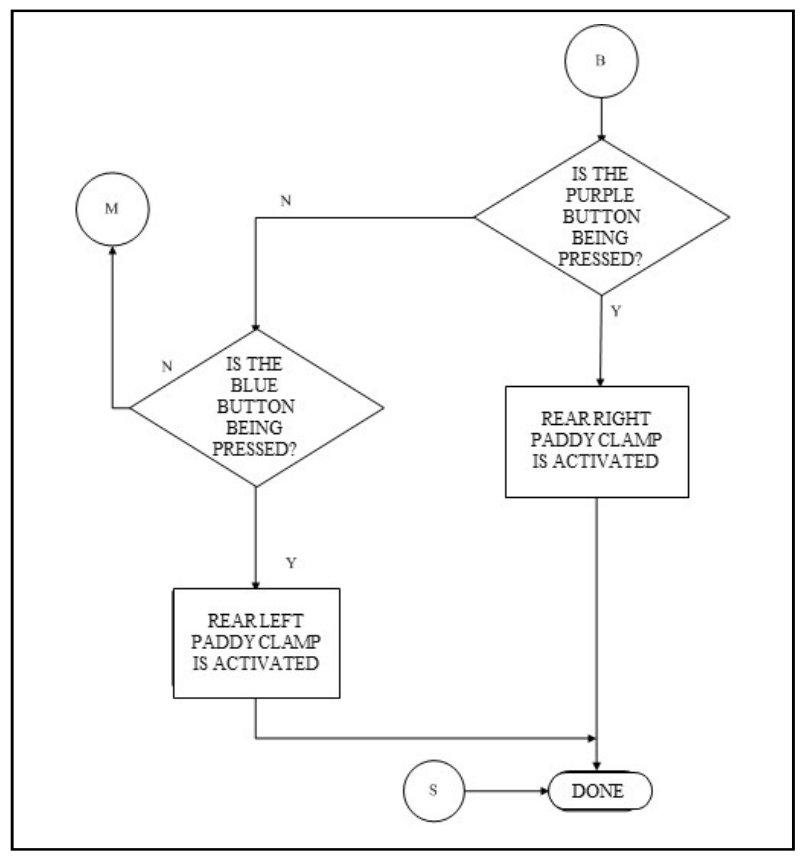

Fig. 8.Primary Joystick Command

- "L2 + down arrow button are pressed?" is a decision making process to determine whether L2 and down arrow button in a joystick are being pressed. If the answer is "Yes", then solenoid valve 2 will be activated and the pneumatic will pull the paddy clamp lever. If it is "No", the operator needs to perform a checking on which button that is going to be pressed.

- "L2 + up arrow button are pressed?" is a decision making process to determine whether L2 and up arrow button in a joystick are being pressed. If the answer is "Yes", then solenoid valve 3 will be activated and the pneumatic will pull the paddy cutter lever. If it is "No", the operator needs to perform a checking on which button that is going to be pressed.

- "Is the red button being pressed?" is a decision making process to determine whether the red button on the joystick is being pressed or not. If the answer is "Yes", then solenoid valve 4 will be activated and the pneumatic will pull the paddy seed 1 paddy clamp lever. If it is "No", the operator needs to perform a checking on which button that is going to be pressed.

- "Is the green button being pressed?" is a decision making process to determine whether the green button on the joystick is being pressed or not. If the answer is "Yes", then solenoid valve 5 will be activated and the pneumatic will pull the paddy seed 2 paddy clamp lever. If it is "No", the operator needs to perform a checking on which button that is going to be pressed.

- "Is the purple button being pressed?" is a decision making process to determine whether the purple button on the joystick is being pressed or not. If the answer is "Yes", then solenoid valve 6 will be activated and the pneumatic will pull the paddy seed 3 paddy clamp lever. If it is "No", the operator needs to perform a checking on which button that is going to be pressed.

- "Is the blue button being pressed?" is a decision making process to determine whether the blue button on the joystick is being pressed or not. If the answer is "Yes", then solenoid valve 7 will be activated and the pneumatic will pull the paddy seed 4 paddy clamp lever. If it is "No", the operator needs to perform a checking on which button that is going to be pressed. 


\subsection{Installation of Pneumatic Cylinder and Solenoid Valve}

Installation of pneumatic cylinder and solenoid valve was carried out by pumping the wind from a compressor to bottle tubes. By using three pieces of tube, it was expected that later on there were more the wind availability, so that the robot was able to navigate more on its actuator[4]. Installation of pneumatic cylinder and solenoid valve can be seen in Figure 9.

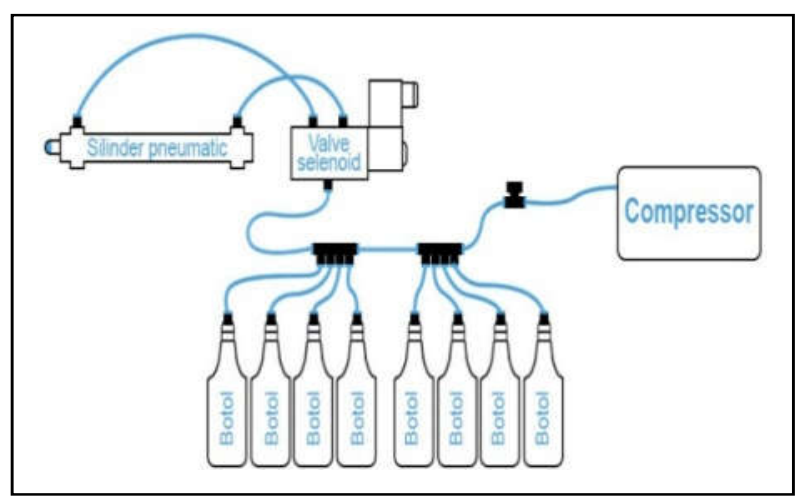

Fig. 9.Installation of pneumatic cylinder and solenoid valve

\section{Results and Discussion}

Testing was performed with a purpose to figure out the result of algorithm design and hardware sub system.

\subsection{Motor Rotation Direction Testing}

There were two variables that were set in DC gearbox motor which were motor rotation direction and motor speed. Motor rotation direction was set by putting some logic into motor driver with the maximum speed.

Table 1. Motor Rotation Direction testing

\begin{tabular}{ccl}
\hline MOUT1 & MOUT2 & \multicolumn{1}{c}{ MOTOR STATE } \\
\hline 1 & 0 & Motor rotates clockwise \\
\hline 0 & 1 & Motor rotates counterclockwise \\
\hline 0 & 0 & Motor does not rotate \\
\hline 1 & 1 & Motor does not rotate \\
\hline
\end{tabular}

\subsection{Motor Driver Efficiency Testing}

Motor DC speed was set by putting analog signal (PWM) into motor driver with the same rotation direction which was clockwise.

Table 2. Motor Driver Efficiency Testing

\begin{tabular}{cccccc}
\hline $\begin{array}{c}\text { Vin } \\
\text { Volt })\end{array}$ & $\boldsymbol{P W M}$ & $\boldsymbol{R P M}$ Motor & $\begin{array}{c}\text { Vout Calculation } \\
(\text { Volt })\end{array}$ & $\begin{array}{c}\text { Vout Measurement } \\
(\text { Volt })\end{array}$ & Efficiency \\
\hline 23,9 & 255 & 515 & 23,9 & 23,9 & $100 \%$ \\
\hline 23,9 & 220 & 444 & 20,51 & 20,61 & $99,5 \%$ \\
\hline 23,9 & 200 & 403 & 18,64 & 18,74 & $99,4 \%$ \\
\hline 23,9 & 180 & 368 & 16,80 & 16,87 & $99,5 \%$ \\
\hline 23,9 & 150 & 306 & 14,04 & 14,05 & $99,9 \%$ \\
\hline 23,9 & 100 & 204 & 9,30 & 9,37 & $99,2 \%$ \\
\hline 23,9 & 80 & 157 & 7,45 & 7,49 & $99,4 \%$ \\
\hline 23,9 & 50 & 96 & 4,68 & 4,68 & $100 \%$ \\
\hline 23,9 & 30 & 50 & 2,68 & 2,81 & $95,37 \%$ \\
\hline 23,9 & 0 & 0 & 0 & 0 & $100 \%$ \\
\hline
\end{tabular}

In order to acquire efficiency value, the equation below was applied:

$$
\text { Vout }=\frac{\text { PWM Value }}{\text { Maximum PWM }} \times \text { Vin }
$$




\subsection{Overall System Testing}

This testing was carried out by combining all the sub systems by viewing the actuator response which was controlled by the joystick. The testing result can be seen in Table 3 .

Table 3. Oveall System Testing

\begin{tabular}{|c|c|c|c|c|}
\hline \multirow{2}{*}{ Command } & \multicolumn{2}{|c|}{ Test 1} & \multicolumn{2}{|c|}{ Test 2} \\
\hline & Success & Fail & Success & Fail \\
\hline Move forward & $\checkmark$ & - & $\checkmark$ & - \\
\hline Move backward & $\checkmark$ & - & $\checkmark$ & - \\
\hline Turn left & $\checkmark$ & - & $\checkmark$ & - \\
\hline Turn right & $\checkmark$ & - & $\checkmark$ & - \\
\hline $\begin{array}{l}\text { Right and left } \\
\text { arm move } \\
\text { inward }\end{array}$ & $\checkmark$ & - & $\checkmark$ & - \\
\hline $\begin{array}{l}\text { Right and left } \\
\text { arm move } \\
\text { inward }\end{array}$ & $\checkmark$ & - & $\checkmark$ & - \\
\hline $\begin{array}{l}\text { Right and left } \\
\text { arm move } \\
\text { inward }\end{array}$ & $\checkmark$ & - & $\checkmark$ & - \\
\hline $\begin{array}{l}\text { Right and left } \\
\text { arm move } \\
\text { inward }\end{array}$ & $\checkmark$ & - & $\checkmark$ & - \\
\hline Arm raises & $\checkmark$ & - & $\checkmark$ & - \\
\hline Arm is down & $\checkmark$ & - & $\checkmark$ & - \\
\hline Arm raises & $\checkmark$ & - & $\checkmark$ & - \\
\hline Arm is down & $\checkmark$ & - & $\checkmark$ & - \\
\hline $\begin{array}{l}\text { Middle arm } \\
\text { clamp }\end{array}$ & $\checkmark$ & - & $\checkmark$ & - \\
\hline Cutting scissor & $\checkmark$ & - & $\checkmark$ & - \\
\hline $\begin{array}{l}\text { Right arm clamp } \\
2 \text { (rear right) }\end{array}$ & $\checkmark$ & - & $\checkmark$ & - \\
\hline $\begin{array}{l}\text { Right arm clamp } \\
1 \text { (front right) }\end{array}$ & $\checkmark$ & - & $\checkmark$ & - \\
\hline $\begin{array}{l}\text { Left arm clamp } \\
1 \text { (front left) }\end{array}$ & $\checkmark$ & - & $\checkmark$ & - \\
\hline $\begin{array}{l}\text { Left arm clamp } \\
2 \text { (rear left) }\end{array}$ & $\checkmark$ & - & $\checkmark$ & - \\
\hline
\end{tabular}

\section{Conclusion}

There are conclusions that can be taken out of this research, which are:

- The maximum control distance from the command joystick to the robot with obstacle free was 50 meter and it did not affect the robot response time.

- Motor driver response efficiency and relay on-off control for the pneumatic which was controlled wirelessly through a joystick reached $99 \%$ and control response success was $100 \%$. 


\section{References}

[1] A. reza Septiadi and S. Amri, "Rancang Bangun dan Analisa Robot Tematik Simulasi Pertanian dengan Kendali Wireless," J. Infomedia Tek. Inform. Multimed. Jar., vol. 4, no. 1, pp. 15-20, 2019.

[2] D. G. Caldwell, G. A. Medrano-Cerda, and M. Goodwin, "Control of pneumatic muscle actuators," IEEE Control Syst. Mag., vol. 15, no. 1, pp. 40-48, 1995.

[3] R. Arifuddin and Y. Sinatra, "Identifikasi Sensor Suhu pada Setup Awal Untuk Pengukuran Suhu Bawah Permukaan," JEECAE (Journal Electr. Electron. Control. Automot. Eng., vol. 3, no. 2, pp. 209-212, 2018.

[4] P. D. P. Adi and R. Arifuddin, "Design Of Tsunami Detector Based Sort Message Service Using Arduino and SIM900A to GSM/GPRS Module," JEEMECS (Journal Electr. Eng. Mechatron. Comput. Sci., vol. 1, no. 1, pp. 1-4, 2018.

[5] Indrawanto, "Panduan Kontes Robot Tematik Indonesia (KRTMI)", Juri Kontes Robot Indonesia, 2019.

[6] Masruri, "Rancang Bangun Robot Manual Pengambil Bola Menggunakan Joystick Wireless", Politeknik Negeri Bengkalis, 2018. 
This page intentionally left blank 